\title{
Hubungan Beberapa Faktor dengan Keluhan Nyeri Punggung Bawah pada Karyawan Kantor
}

\author{
Relationship Betwen Several Factor and With Low Back Pain on Office \\ Employees
}

\section{Kamali Zaman}

\author{
Pascasarjana Ilmu Lingkungan Program Pascasarjana Universitas Riau Pekanbaru
}

\begin{abstract}
ABSTRAK
Kantor merupakan lingkungan tempat kerja dan harus memenuhi ketentuan dalam Workplace (Health, Safety and Welfare). Walaupun kantor secara umum dipandang aman, namun di dalamnya tetap memuat bahaya kesehatan yang dapat menyebabkan cedera serius. Salah satu bentuk gangguan yang dapat timbul akibat lingkungan kerja khususnya di lingkungan kerja perkantoran adalah nyeri punggung bawah. Populasi dalam penelitian ini adalah karyawan STIKes Hang Tuah Pekanbaru yang bekerja sebagai staf bagian akademik. Sedangkan sampel dalam penelitian ini adalah seluruh populasi yang memenuhi kriteria sebagai sampel dalam penelitian. Penelitian ini dilakukan untuk mengetahui hubungan antara ergonomi kursi dan meja serta sikap duduk dengan keluhan nyeri punggung bawah pada karyawan kantor. Penelitian ini menggunakan metode cross sectional study dengan jumlah sampel sebanyak 63 karyawan. Variabel independen dalam penelitian ini adalah Indek Masa Tubuh (IMT), Umur, sikap duduk, ergonomi kursi dan meja, waktu kerja dan lama kerja. Analisis data dilakukan secara univariat, bivariat dan multivariat. Hasil penelitian menunjukan ada tiga variabel yang memiliki hubungan dengan kejadian nyeri punggung bawah yaitu Indek Masa Tubuh (IMT), Umur, Sikap duduk. Analisis multivariat menunjukan bahwa sikap duduk yang tidak baik memiliki hubungan dengan keluhan nyeri punggung bawah 40 kali lebih berpotensi dibandingkan dengan karyawan dengan sikap duduk yang benar (CI 95\%: OR $=40)$.
\end{abstract}

Kata kunci: Ergonomi, Nyeri Punggung Bawah, Sikap Duduk

\section{ABSTRACT}

The office is the neighborhood where work and must be fulfilled the provisions in the workplace ( health, safety and welfare ). Although the office in general is considered safe, but in it still contain health danger that can lead to serious injury. One form of a nuisance that can arise due to a work environment especially in a work environment office is pain the lower back. Population in this research are employees stikes hang tuah pekanbaru who works as a staff of academic. While a sample in this research is the whole population of which satisfies the criteria as a sample in research. The aim of this research to analyze the relationship of Ergonomic Desk Chair and Posture With Low Back Pain on Office Employees. The research method is Analytic Cross Sectional Study with sampling method and 63 employes as sample. Independent variable of this research is body mass index, age, posture, ergonomic desk chair, working time and working olg. Analysis is doing by univariat, bivariate and multivariate. The result obtained is 3 variables that relationship With Low Back Pain on Office Employees that is, body mass index, age, posture. From multivariate analysis acquired that bad posture the most dominant variable that relationship with Low Back Pain, 40 time having low back pain more than worker that good posture (CI 95\% : $O R=40)$.

Key words : Ergonomic, Low Back pain, Sitting Posture

\section{PENDAHULUAN}

Lingkungan kerja sangat berkaitan dengan keadaan disekitar aktivitas pekerja dalam melakukan pekerjaanya. Interaksi antar pekerja, pekerjaan dan lingkungan kerja tentu saja tidak dapat dihindari karena merupakan bagian dari aktivitas kehidupan. Lebih dari 35\% waktu dalam kehidupan pekerja yang bekerja berada dalam lingkungan pekerjaanya (Budiono et al., 2008). Secara spesifik, lingkungan kerja fisik merupakan semua keadaan berbentuk fisik yang terdapat di sekitar tempat kerja yang dapat mempengaruhi karyawan baik secara langsung maupun scara tidak langsung.
Kajian ilmiah hubungan antara pekerjaan dengan kesehatan seseorang bukanlah hal yang baru di lingkungan kerja. Budiono et al. (2008) Menyatakan bahwa konsep kesehatan kerja dewasa ini semakin banyak berubah, bukan sekedar hanya kesehatan pada sektor industri saja melainkan kepada upaya kesehatan untuk semua orang dalam melakukan pekerjaanya (total health of all at work).

Kantor merupakan lingkungan tempat kerja dan harus memenuhi ketentuan dalam Workplace (Health, Safety and Welfare). Walaupun kantor secara umum dipandang aman, namun di dalamnya tetap

Alamat Korespodensi : M. Kamali zaman, Jl. Pattimura No.09 Gobah, Hp: 085272165118, Email: kmlzaman@gmail.com 
memuat bahaya kesehatan yang dapat menyebabkan cedera serius. Sedangkan sebagian besar kecelakaan dan masalah kesehatan kerja di kantor semata-mata disebabkan oleh sikap kerja dan dapat dihindari dengan cara meningkatkan kepedulian, memperhatikan keadaan sekitar dan memperlakukan peralatan kerja dengan baik (Ridley, 2003). Untuk dapat memperkecil pengaruh lingkungan fisik terhadap karyawan, maka langkah pertama adalah harus mempelajari manusia, baik mengenai fisik dan tingkah lakunya maupun mengenai fisiknya, kemudian digunakan sebagai dasar memikirkan lingkungan fisik yang sesuai.

Penyakit-penyakit akibat lingkungan kerja telah lama dikenal dan diketahui termasuk penyakit nyeri pada bagian punggung bawah atau sering disebut dengan nyeri punggung bawah. Nyeri punggung bawah merupakan fenomena yang seringkali dijumpai pada setiap lingkungan kerja. Insidens dan beratnya gangguan nyeri punggung bawah lebih sering dijumpai pada pekerja wanita dibandingkan laki-laki. Posisi statis dalam bekerja kadang-kadang tidak dapat terhindarkan. Samara et al., (2005) menyatakan penyakit ini digolongkan pada penyakit ortopedi menyangkut sistem muskulo skeletal yang erat kaitanya dengan kelainan gangguan gerak akibat trauma atau penyakit, yang mengakibatkan kelainan anatomik maupun kelainan fungsi yang dapat timbul akibat suatu keadaan akut atau kronik berulang.

Salah satu bentuk gangguan yang dapat timbul akibat lingkungan kerja khususnya di lingkungan kerja perkantoran adalah nyeri punggung bawah. Nyeri punggung bawah merupakan salah satu gangguan muskuloskletal yang disebabkan oleh aktivitas tubuh yang kurang baik. Nyeri punggung bawah dapat disebabkan oleh berbagai penyakit muskuloskeletal, mobilisasi yang salah. Nyeri punggung bawah merupakan masalah umum kesehatan di lingkungan kerja yang menyebabkan ketergantungan dalam penggunaan layanan kesehatan. Sulitnya menegakkan diagnosis, prevalensi yang terus meningkat dan meningkatnya hari kerja yang hilang, menyebabkan meningkatnya biaya yang diperlukan untuk penanganan nyeri punggung bawah baik biaya langsung, maupun tidak langsung. Diharapkan dengan penelitian ini, dapat diketahui besaran masalah nyeri punggung bawah serta faktor-faktor yang mempengaruhinya. Dengan demikian, ada upaya yang dapat dilakukan guna mengatasi masalah yang ada.

\section{METODE}

Penelitian ini dilakukan dengan jenis disain analitik cross sectional. Penelitian ini dilakukan di Sekolah Tinggi Ilmu Kesehatan (STIKes) Hang Tuah Pekanbaru pada bulan Desember 2013. Populasi dalam penelitian ini adalah karyawan STIKes Hang Tuah Pekanbaru yang bekerja sebagai staf bagian akademik. Sedangkan sampel dalam penelitian ini adalah seluruh populasi yang memenuhi kriteria sebagai sampel dalam penelitian.

Pengumpulan data dilakukan dengan cara memberikan kuesioner kepada responden serta dilakukan pengamatan terkait sikap duduk dalam bekerja. Kuesioner terkait dengan data diri dan keluhan nyeri punggung bawah yang dibuat mengacu pada telaah kepustakaan. Selain itu, observasi juga dilakukan dengan mengacu pada sikap duduk karyawan. Kuesioner dan panduan observasi juga telah dilakukan uji validitas dan reabilitas untuk memastikan ketepatan dan konsistensi jawaban kuesioner. Dalam penelitian yang dilakukan, analisis statistik yang digunakan untuk data kategorik pada variabel independen dan data kategorik pada variabel dependen menggunakan jenis uji regresi logistik.

\section{HASIL}

Tabel 1

Distribusi Karyawan Yang Mengalami Keluhan Nyeri Punggung Bawah

$(n=63)$

\begin{tabular}{lcc}
\hline $\begin{array}{c}\text { Nyeri Punggung } \\
\text { Bawah }\end{array}$ & Jumlah & Persentase \\
\hline Tidak & 10 & $15.9 \%$ \\
Ya & 53 & $84.1 \%$ \\
\hline Total & $\mathbf{6 3}$ & $\mathbf{1 0 0 \%}$ \\
\hline
\end{tabular}

Tabel 2

Distribusi Frekuensi Keluhan Nyeri Punggung Bawah $(\mathbf{n}=63)$

\begin{tabular}{|c|c|c|c|}
\hline No & Faktor-faktor & $\begin{array}{c}\text { Jumlah } \\
\text { (n) }\end{array}$ & Persentase \\
\hline \multirow[t]{3}{*}{1} & Indek masa tubuh & & \\
\hline & $\begin{array}{l}\text { Normal }(18,6-24,9 \\
\left.\mathrm{kg} / \mathrm{m}^{2}\right)\end{array}$ & 45 & 20 \\
\hline & $\begin{array}{l}\text { Tidak normal }(\leq 18,5 \\
\left.\text { atau } \geq 30 \mathrm{~kg} / \mathrm{m}^{2}\right)\end{array}$ & 42 & 43 \\
\hline \multirow[t]{3}{*}{2} & Umur & & \\
\hline & Ideal (20-30) & 28 & 44. \\
\hline & $\begin{array}{l}\text { Berisiko }(\leq 19 \text { atau } \geq \\
\text { 31) }\end{array}$ & 35 & 55. \\
\hline \multirow[t]{3}{*}{3} & $\begin{array}{l}\text { Ergonomi kursi dan } \\
\text { meja }\end{array}$ & & \\
\hline & Ergonomis & 56 & 88.9 \\
\hline & Tidak ergonomis & 7 & 11.1 \\
\hline \multirow[t]{3}{*}{4} & Sikap duduk & & \\
\hline & - Ergonomis & 12 & 19 \\
\hline & - Tidak Ergonomis & 51 & 81 \\
\hline \multirow[t]{3}{*}{5} & Waktu Kerja & & \\
\hline & - Ideal (<8jam) & 35 & 55,6 \\
\hline & - Tinggi (>8jam) & 28 & 44,4 \\
\hline \multirow[t]{4}{*}{6} & Masa Kerja & & \\
\hline & - Rendah ( $\leq 5$ tahun $)$ & 37 & 58,7 \\
\hline & - Tinggi ( $>5$ tahun) & 26 & 41,3 \\
\hline & Total & 63 & 100 \\
\hline
\end{tabular}




\section{Analisis Univariat}

Hasil penelitian menggambarkan situasi keadaan fisik kantor dan keadaan karyawan yang bekerja pada tempat penelitian. Hasil penelitian dibagi kedalam dua bagian yaitu distribusi keluhan nyeri punggung bawah pada karyawan kantor serta faktor yang mempengaruhinya (IMT, umur, ergonomi kursi dan meja, sikap duduk, waktu kerja dan masa kerja). Selain itu, hasil uji statistik (Bivariat dan multivariat) menunjukan korelasi variabel indenden dengan kejadian keluhan nyeri punggung bawah pada karyawan kantor. Tabel 1 menunjukan jumlah karyawan STIKes Hang Tuah Pekanbaru yang mengalami keluhan nyeri punggung adalah sebanyak
53 karyawan (84.1\%). Tabel 2 menunjukan bahwa terdapat $68,3 \%$ IMT tidak normal, 55,6 umur berisiko, ergonomi kursi dan meja $11,1 \%$, sikap duduk tidak ergonomis $81 \%$, waktu kerja tinggi $44,4 \%$ serta masa kerja $41,3 \%$.

\section{Analisis Bivariat}

Untuk melihat hubungan antara kejadian keluhan nyeri punggung bawah dengan variabel yang mempengaruhinya, dilakukan analisis hubungan antara variabel hingga didapatkan hasil seperti tabe1 3. Pada tabel 3 menunjukan bahwa sikap duduk yang tidak ergonomis berisiko 11,8 kali mengalami keluhan nyeri punggung bawah dibandingkan dengan sikap duduk yang ergonomis (CI 95\%: OR 2,6 - 54).

Tabel 3

Hubungan variabel independen dengan variabel dependen

\begin{tabular}{|c|c|c|c|c|c|c|c|}
\hline & \multicolumn{2}{|c|}{ Keluhan Nyeri } & \multirow{2}{*}{ Nilai $\mathbf{P}$} & \multirow{2}{*}{ POR } & \multicolumn{2}{|c|}{ CI $(95 \%)$} \\
\hline & & Ya & Tidak & & & Lower & Uper \\
\hline \multirow[t]{3}{*}{ IMT } & $\begin{array}{l}\text { Tidak normal }(\leq 18,5 \text { atau } \\
\left.\geq 30 \mathrm{~kg} / \mathrm{m}^{2}\right)\end{array}$ & $43(81,1 \%)$ & $0(0 \%)$ & \multirow{3}{*}{0,000} & \multirow{3}{*}{0,500} & \multirow{3}{*}{0,323} & \multirow{3}{*}{0,775} \\
\hline & $\begin{array}{l}\text { Normal } \backslash(18,6-24,9 \\
\left.\mathrm{kg} / \mathrm{m}^{2}\right)\end{array}$ & $10(18,9 \%)$ & $10(100 \%)$ & & & & \\
\hline & & $53(100 \%)$ & $10(100 \%)$ & & & & \\
\hline \multirow[t]{3}{*}{ Umur } & Berisiko $(\leq 19$ atau $\geq 31)$ & $33(62,3 \%)$ & $2(20 \%)$ & \multirow[t]{3}{*}{0,016} & \multirow[t]{3}{*}{6,600} & \multirow[t]{3}{*}{1,273} & \multirow[t]{3}{*}{34,23} \\
\hline & Ideal (20-30 tahun) & $20(37,7 \%)$ & $8(80 \%)$ & & & & \\
\hline & & $53(100 \%)$ & $10(100 \%)$ & & & & \\
\hline \multirow{3}{*}{$\begin{array}{l}\text { Ergonomi kursi } \\
\text { dan meja }\end{array}$} & Tidak ergonomi & $6(11,3 \%)$ & $1(10 \%)$ & \multirow[t]{3}{*}{0,694} & \multirow[t]{3}{*}{1,149} & \multirow[t]{3}{*}{0,123} & \multirow[t]{3}{*}{10,72} \\
\hline & Ergonomi & $47(88,7 \%)$ & $9(90 \%)$ & & & & \\
\hline & & $53(100 \%)$ & $10(100 \%)$ & & & & \\
\hline \multirow[t]{3}{*}{ Sikap duduk } & Tidak ergonomi & $47(88,7 \%)$ & $4(40 \%)$ & \multirow[t]{3}{*}{0,002} & \multirow[t]{3}{*}{11,750} & \multirow[t]{3}{*}{2,560} & \multirow[t]{3}{*}{53,93} \\
\hline & Ergonomi & $6(11,3 \%)$ & $6(60 \%)$ & & & & \\
\hline & & $53(100 \%)$ & $10(100 \%)$ & & & & \\
\hline \multirow[t]{3}{*}{ Waktu kerja } & Tinggi & $24(45,3 \%)$ & $4(40 \%)$ & \multirow[t]{3}{*}{0,519} & \multirow[t]{3}{*}{1,241} & \multirow[t]{3}{*}{0,314} & \multirow[t]{3}{*}{4,941} \\
\hline & Ideal & $29(54,7 \%)$ & $6(60 \%)$ & & & & \\
\hline & & $53(100 \%)$ & $10(100 \%)$ & & & & \\
\hline \multirow[t]{3}{*}{ Masa kerja } & Tinggi & $22(41,5 \%)$ & $4(40 \%)$ & \multirow[t]{3}{*}{0,608} & \multirow[t]{3}{*}{1,065} & \multirow[t]{3}{*}{0,268} & \multirow[t]{3}{*}{4,223} \\
\hline & Rendah & $31(58,5 \%)$ & $6(60 \%)$ & & & & \\
\hline & & $53(100 \%)$ & $10(100 \%)$ & & & & \\
\hline
\end{tabular}

\section{Analisis Multivariat}

\section{Seleksi Bivariat}

Tabel 4 menunjukan variabel yang masuk kedalam pemodelan multivariat diantaranya IMT, Umur dan Sikap duduk. Karena ergonomi kursi dan meja merupakan variabel utama, maka dimasukan kedalam seleksi untuk dilakukan analisis.

\section{Pemodelan Akhir analisis multivariat}

Tabel 5 menunjukan bahwa ada hubungan sikap duduk yang tidak ergonomis dengan keluhan nyeri punggung bawah. Sikap duduk yang tidak ergonomis 40 kali berisiko mengalami keluhan nyeri punggung bawah dibandingkan dengan sikap duduk yang ergonomis.
Tabel 4

Hasil seleksi bivariat

\begin{tabular}{lcc}
\hline \multicolumn{1}{c}{ Variabel } & Nilai P & Keterangan \\
\hline IMT & $\mathbf{0 , 0 0 0}$ & Kandidat \\
Umur & $\mathbf{0 , 0 1 6}$ & Kandidat \\
Ergonomi kursi dan meja & $\mathbf{0 , 6 9 4}$ & Bukan \\
& & Kandidat \\
Sikap duduk & $\mathbf{0 , 0 0 2}$ & Kandidat \\
Waktu kerja & 0,519 & Bukan \\
& & Kandidat \\
Masa kerja & 0,608 & Bukan \\
& & Kandidat
\end{tabular}


Tabel 5

Pemodelan Akhir Analisis Multivariat

\begin{tabular}{|c|c|c|c|c|c|c|c|c|}
\hline \multirow[t]{2}{*}{ Variabel Independen } & \multirow[t]{2}{*}{ B } & \multirow[t]{2}{*}{ S.E. } & \multirow[t]{2}{*}{ Wald } & \multirow[t]{2}{*}{ df } & \multirow[t]{2}{*}{ Sig. } & \multirow[t]{2}{*}{$\operatorname{Exp}(B)$} & \multicolumn{2}{|c|}{$\begin{array}{c}\text { 95.0\% C.I. for } \\
\operatorname{Exp(B)}\end{array}$} \\
\hline & & & & & & & Lower & Uper \\
\hline Sikap duduk & 3,699 & 1,445 & 6,554 & 1 & 010 & 40,426 & 2,380 & 686,623 \\
\hline Ergo meja dan kursi & $-15,190$ & 5241,048 &, 000 & 1 & ,998 & ,000 & ,000 & \\
\hline IMT & 31,818 & 7312,027 & ,000 & 1 & ,997 & 0065 & ,000 & \\
\hline Umur & 1,421 & 1,464 & ,942 & 1 & ,332 & 4,139 & 235 & 72,927 \\
\hline Constant & $-25,107$ & 5098,751 & 000 & 1 & ,996 & ,000 & & \\
\hline
\end{tabular}

\section{PEMBAHASAN}

Pengambilan sampel dalam penelitian ini total sampling sejumlah 63 karyawan. Jumlah ini tidak ditentukan menurut jenis disain penelitian (Analitik Cross Sectional) memungkinkan ukuran sampel terlalu kecil, sehingga hanya 1 variabel (sikap duduk) dari 6 variabel independen yang berhubungan dengan nyeri punggung bawah pada karyawan. Hasil penelitian ini hanya terbatas pada 63 karyawan yang diteliti.

Dalam penelitian ini terbukti bahwa karyawan yang sikap duduk tidak ergonomis berisiko 40 kali menderita keluhan nyeri punggung bawah dibandingkan dengan karyawan dengan sikap duduk ergonomis. Karena begitu tingginya POR (40 kali) kemungkinan ada hubungan sebab akibat antara sikap duduk dengan kejadian nyeri punggung : sikap duduk tidak ergonomis mempengaruhi karyawan untuk mengalami keluhan nyeri punggung bawah 40 kali dibandingkan dengan sikap duduk ergonomis. Karena itu direkomendasikan agar karyawan tidak menderita keluhan nyeri punggung bawah, karyawan harus melakukan sikap duduk yang ergonomis.

Postur tubuh karyawan dalam bekerja menentukan sikap karyawan dalam bekerja. Berdiri, duduk membungkuk dan lain-lain merupakan bagian dari banyaknya sikap duduk yang dilakukan oleh karyawan tergantung dari kondisi dari sistem kerja yang ada. Keluhan nyeri punggung bawah yang terjadi pada karyawan terkait sikap duduk pada karyawan terjadi dipicu oleh sikap duduk yang tidak beraturan, karena dapat menyebabkan keluhan akut akibat cedera karena sikap duduknya.

Keluhan nyeri punggung bawah dapat terjadi karena kasalahan dalam sikap duduk serta durasi waktu duduk dalam melakukan pekerjaan. Tanpa disadari, karyawan melakukan kegiatan duduk pada posisi yang sama dalam waktu yang lama. Selain itu, sikap duduk yang tidak alamiah dan terkesan dipaksakan menjadi faktor pemicu keluhan nyeri punggung bawah.

Santoso (2012) menyatakan bahwa posisi kerja yang tidak alamiah/janggal, aktifitas berulang-ulang serta posisi kerja statis merupakan faktor risiko terjadinya gangguan otot rangka (keluhan nyeri punggung bawah). Pada posisi duduk, tekanan tulang belakang akan meningkat dibanding berdiri atau berbaring, jika posisi duduk tidak benar. Tekanan posisi tidak duduk $100 \%$, maka tekanan akan meningkat menjadi $140 \%$ bila sikap duduk tegang dan kaku, dan tekanan akan meningkat menjadi 190\% apabila saat duduk dilakukan membungkuk kedepan.

Kecendrungan sikap duduk yang dilakukan karyawan adalah posisi kifosis (membengkok ke belakang) seperti pada tabel penelitian, dimana sikap duduk membengkok ke belakang mendapatkan jumlah skor yang tinggi dibandingkan dengan posisi yang lain. Selain itu, sikap tidak beraturan ketika melakukan pekerjaan atau hanya sekedar bermain game juga menjadi kebiasaan dari beberapa responden penelitian. Sikap duduk yang tidak ergonomis juga terjadi pada karyawan pada saat tidak melakukan pekerjaan .Berikut sikap duduk yang tidak beraturan yang dilakukan oleh karyawan.

Pendekatan kenyamanan tempat duduk pada perancangan tempat duduk ditekankan pada penelitian kemampuan keterbatasan manusia, baik secara fisik maupun mental psikologis dan interaksinya dalam sistem manusia dan lingkungan kerja yang integral.

\section{KESIMPULAN}

Berdasarkan hasil penelitian didapatkan bahwa keluhan nyeri punggung bawah pada karyawan kantor merupakan fenomena yang sering terjadi, namun sering diabaikan dan tidak dianggap sebagai masalah. Uji statistik menunjukan bawa beberapa variabel memiliki hubungan dengan keluhan nyeri punggung bawah sedangkan variabel yang lainya tidak memiliki hubungan. Variabel yang memiliki hubungan yang dimaksud adalah IMT, Umur dan sikap duduk. Sedangkan variabel ergonomi kursi dan meja, waktu kerja dan masa kerja tidak menunjukan hubungan dengan keluhan nyeri punggung bawah. Analisis multivariat menggambarkan bahwa faktor sikap duduk yang buruk dalam bekerja menyebabkan 40,426 kali lebih berisiko mengalami keluhan nyeri punggung bawah dibandingkan dengan sikap duduk yang benar. 


\section{SARAN}

Atas dasar pembahasan diatas, disarankan agar setiap perangkat komputer atau laptop menggunakan aplikasi pengingat waktu agar karyawan bekerja sesuai dengan waktu yang sesuai. Upaya ini dilakukan agar karyawan tidak melakukan sikap duduk statis, dan melakukan gerakan dinamis setiap kali 15 menit selama melakukan pekerjaan.

\section{DAFTAR PUSTAKA}

Budiono , S., R.M.S. jusuf, dan A. Pusparini. 2008. HIPERKES\&KK. Edisi Ketiga. Universitas Diponegoro. Semarang.

Ridley., 2003, Kesehatan dan Keselamatan Kerja.
Samara, D., B. Basuki, dan J. Jannis. 2005. Duduk Statis Sebagai Faktor Risiko Terjadinya Nyeri Punggung Bawah pada Pekerja Perempuan. Jurnal Universa Medicina 24 (2).

Santoso, 2012. Kesehatan dan Keselamatan Kerja, UNS Press. Surakarta.

Suma'mur., 1996, Higene Perusahaan dan Kesehatan Kerja, PT Toko Agung, Jakarta.

Tulaat, A.B.M. 2008. Nyeri Leher dan Punggung, Majalah Kedokteran Indonesia Vol 58 (5).

Septiawan, H. 2013. Faktor Berhubungan Keluhan Nyeri Punggung Bawah Pada Pekerja Bangunan. Jurnal Unnes Journal Of Public Health 3(2): 1-8. 